\title{
Development of a Framework for Strategic Outsourcing in Developing Countries
}

\author{
Maaz Ahmed Qureshi, Muhammad Salman, and Rameez Khalid
}

\begin{abstract}
Outsourcing is a phenomenon that has changed the global business scenario. A practically applicable framework has been developed and tested in order to provide a tool for manufacturing industries for making decision regarding outsourcing. The main purpose of this paper is to target those countries where outsourcing manufacturing is still a new concept and provide them with an easy to follow framework. This framework will make the process of decision analysis easier and reliable for them. The proposed framework is a step by step model which by using core competency check, decision matrix, balance score card models and cost equations makes sure that the organization makes the right decision regarding whether a particular activity should be outsourced or not.
\end{abstract}

Index Terms-Balance score cards, core competency, framework, outsourcing.

\section{INTRODUCTION}

Outsourcing is the act of transferring organization's decision and manufacturing rights of recurring and unimportant activities to vendors or contract-manufacturers [1]. This research aims on establishing a framework which will ensure successful outsourcing in developing countries where In-House manufactured parts development through vendors is still a new concept. Application of this framework is not limited to any particular industry and efforts have been made to make it as much general and simple as possible.

Through outsourcing original equipment manufacturers find themselves in a better position to meet market requirements and deal with increasing price and exuberant profit pressures. This strategy is also helping the organizations with forming more specialized products at lower costs and higher quality [2].

Outsourcing has become so popular because by relying on strategic outsourcing, companies can focus on their core competencies, moreover they can take advantage of low overhead costs, for e.g. labor cost in ford company in USA is $65 \$$ per hour whereas in China its $2 \$$ which clearly indicates that how strategic outsourcing can benefit organizations and reduce their overall cost [3].

Since outsourcing has now became a key part of company's strategy for effectively managing supply and cost therefore the risk associated with this process must be

Manuscript received December 25, 2012; revised February 10, 2013.

Maaz Ahmed Qureshi and Muhammad Salman are with the NED University of Engineering and Technology and currently working as Planning Engineer in private sector Manufacturing Industry (e-mail: \{ahmedmaaz89, muhammad.salman\}@ hotmail.com).

Rameez Khalid is with the Industrial and Manufacturing Engineering Department, NED University of Engineering \& Technology, Karachi, 75270 Pakistan (e-mail: rameez.khalid@neduet.edu.pk). properly analyzed and managed. Relying on third party for manufacturing of a certain product brings significant risks of declining customer satisfaction level due to unforeseen delays and other hiccups [4]. Such delays are dependent on many factors such as port/ custom delays, labor strikes or unrest in law and order situation. Another problem which organizations might face while outsourcing there manufacturing processes is the deterioration in product quality [5]. These are various reasons that forced numerous organizations in Pakistan to move towards vertical integration and conglomeration i.e. moving away from outsourcing.

Careful selection of vendors, contract manufacturers or strategic partners shall be done during evaluation phase in order to maintain quality of the product. Supply interruption is another nightmare for companies involved in contract manufacturing. The supplier may prove to be not enough financially viable to provide on time supplies through the project duration which may result in production loss of customers due to [6].

In this paper we have focused on developing a framework for strategic outsourcing in developing countries which is based on decision matrix , core competency check and further supported by balance score card models and cost equations in order to ensure a reliable framework which helps organization in making a safe and accurate decision regarding outsourcing.

\section{FRAMEWORK}

Much has been discussed regarding outsourcing strategies and different frameworks have also been given by [7] and [8] but either it seems to be quite difficult to follow for countries that are new to outsourcing concept or they have limited practical application to certain specific industries [9].

In order to analyze the effect of purchasing cost reduction on the net profit data of Table I was used to carry out analysis shown in Table II by using (1). It is quite clear from the analysis that only a ten percent reduction in purchasing cost resulted in 69 percent increment in profit of an organization whereas for earning same profit, sales cost had to be increased by 69 percent or labor cost has to be decreased by 37 percent keeping everything constant. Since outsourcing greatly reduces purchasing cost of organizations, therefore it's a quite profitable option for industries in developing countries.

$$
\text { Pre }- \text { Tax Profit }=\text { Sales }-(\text { Purchase }+ \text { labor }+ \text { overheads })
$$

The flowchart in Fig. 1 shows our entire framework which starts from ' $A$ ' core competency check which checks whether 
or not the activity is core competency of organization is the decision is marginal or negative then we will proceed to ' $B$ ' decision matrix for firm decision and if still decision is marginal than ' $C$ ' cost equations are used to come to a conclusion that whether or not a particular activity shall be outsourced.

TABLE I: DATA TAKEN FROM ANNUAL REPORT OF ELECTRONICS MANUFACTURING INDUSTRY OF PAKISTAN ${ }^{1}$

\begin{tabular}{cc}
\hline Heads & Costs (Million) \\
\hline Sales & Rs. 100 \\
Purchase & Rs. 55 \\
Labor & Rs. 15 \\
Overheads & Rs. 22 \\
\hline
\end{tabular}

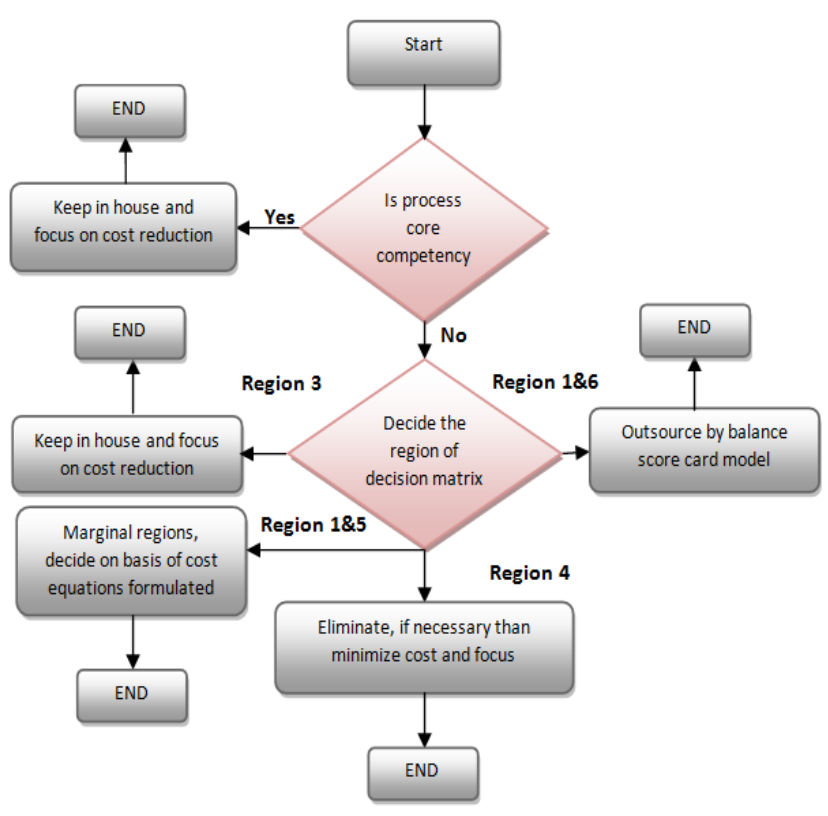

Fig. 1. Flowchart for strategic outsourcing [10].

TABLE II: ANALYZING THE EFFECT OF PURCHASING COST REDUCTION ON NET PROFIT OF AN ORGANIZATION (IN MILLIONS)

\begin{tabular}{cccc}
\hline Heads & $\begin{array}{c}\text { Reduce } \\
\text { purchase cost } \\
\text { by 10\% }\end{array}$ & $\begin{array}{c}\text { Increase sales } \\
\text { by 69\% }\end{array}$ & $\begin{array}{c}\text { Reduce } \\
\text { Labor cost } \\
\text { by 37\% }\end{array}$ \\
\hline Sales & 100 & 168.7 & 100 \\
Purchases & 49.5 & 92.8 & 55 \\
Labor & 15 & 25.3 & 95 \\
Overheads & 22 & 37.1 & 22 \\
\hline Pre-Tax & 13.5 & 13.5 & 13.5 \\
Profit & & & \\
\hline
\end{tabular}

\section{A. Core Competency Check}

The concept of core competency is quite old and is based on the concept of resource based theory [11] . It is defined as the process of collective learning in an organization focusing on out beating competitors by developing diversified production skills. It is very important for an organization to know what are its core competencies [12].

Mentioned in Table III is the checklist which shall be analyzed by the top management before opting for outsourcing, this is the first and most important step towards making a decision that whether a certain process shall be outsourced or not. If the end result of this checklist is negative or marginal then there exists a need to follow rest of

\footnotetext{
${ }^{1}$ Name of the Industry is confidential. Data may be furnished on request.
}

the framework steps in order to reach a conclusion. However if the result is positive then the activity must be kept in house and focus must be kept on cost reduction.

\section{TABLE III: CORE COMPETENCY CHECKLIST}

Is there a need of highly specialized design or labor skills to

perform the activity under consideration?

Whether or not the activity touches the end user's experience to a high extent?

Is the activity a specialty of your organization and requires technical skills which are very rare in market?

Does the activity allow provision for wide variety of possible future markets?

\section{B. Decision Matrix}

Decision matrix is achart based on certain parameters which makes decision process easier and yet reliable. Our matrix is of graphical type (Fig. 2) based on parameters defined on $\mathrm{x}$ and $\mathrm{y}$-axis which helps in making the analysis that whether a certain manufacturing activity shall be outsourced or not.

If the result of core competency check is negative or marginal then the product under consideration shall be analyzed on the decision matrix in order to figure out whether it shall be outsourced or kept in house.

The decision matrix has been divided into six regions. The $\mathrm{x}$-axis of the decision matrix shows how critical the component under consideration is to the final product that is up to what extent it touches the customers' experience. Whereas the y-axis shows the strategic importance of the component that is if or not the company will add value or gain competitive advantage by focusing on the manufacturing of that product. Significance of each region of decision matrix is explained below, organizations must themselves decide strategic value as high, marginal and low and criticality as high or low.

Region 1: It caters those elements which are quite less critical to the final product but they have a high strategic value, so for these products it's neither feasible to keep them in house since they will disturb the focus of the components which contribute greatly towards the criticality of the final product.

Nor they can be outsourced blindly to a manufacturer since they have a high strategic value and if done smoothly can help the organization gaining competitive advantage over other.

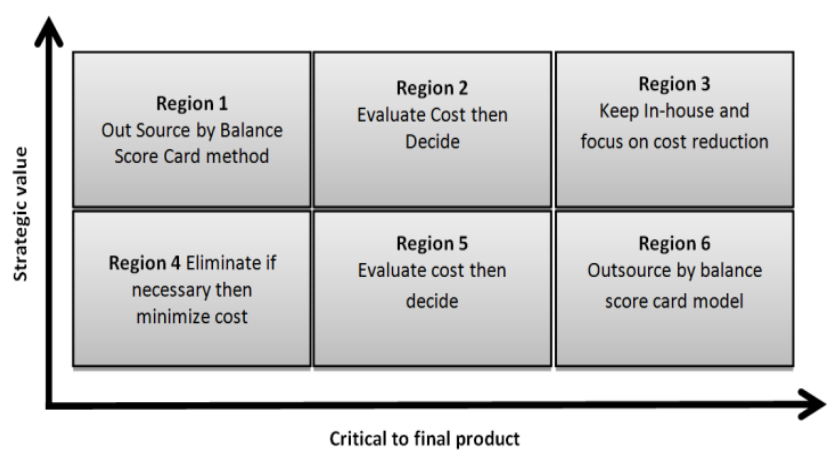

Fig. 2. Decision matrix for outsourcing region selection. 
TABLE IV: BALANCE SCORE CARD MODEL FOR REGION 1

\begin{tabular}{cccccc}
\hline & \multicolumn{2}{c}{ Rating of suppliers } & \multicolumn{2}{c}{ Ranking of suppliers } \\
\hline Factors & Weight & Supplier & Supplier & Supplier & Supplier \\
& A & B & A & B \\
\hline Maturity & & & & \\
Price & & & & \\
Location & & & & \\
Quality & & & & \\
\hline
\end{tabular}

So for these components its best to go for outsourcing through pilot lots. Lot from potential supplier shall be evaluated on the basis of balance score card model given in Table IV.

The balance score card model shown in Table $\mathrm{V}$ provides the proper procedure for supplier evaluation. All the factors have been selected carefully considering the fact that the strategic importance is high; each factor must be assigned a weight according to its importance; and supplier must be rated out of 10 for each of the factor. Ranking of the suppliers is calculated by following procedure: Multiply rating of each supplier with the corresponding weight then sum the rating and assign a rank to each supplier based on their cumulative rating. Supplier with highest rating will get the first rank and so on. Outsource the component to the supplier which proves to be the best on the balance score card model

Region 3: Elements lying in region 3 are quite critical to the final product and have high strategic value so they should not be outsourced since their smooth production can help company to gain competitive advantage and increase its business volume. Therefore it is recommended that they shall be kept in house.

Region 4:Caters those elements which are neither critical to the final product nor have significant strategic value, so for these products our paper proposes to evaluate if the component can be eliminated somehow or not, and if it is essential then minimum focus and energy shall be wasted on it.

TABLE V: BALANCE SCORE CARD MOdel FOR Region 6

\begin{tabular}{|c|c|c|c|c|c|}
\hline \multirow[b]{2}{*}{ Factors } & \multirow[b]{2}{*}{ Weight } & \multicolumn{2}{|c|}{ Rating of suppliers } & \multicolumn{2}{|c|}{ Ranking of suppliers } \\
\hline & & $\begin{array}{l}\text { Supplier } \\
\text { A }\end{array}$ & $\begin{array}{l}\text { Supplier } \\
\text { B }\end{array}$ & $\begin{array}{l}\text { Supplier } \\
\text { A }\end{array}$ & $\begin{array}{l}\text { Supplier } \\
\text { B }\end{array}$ \\
\hline $\begin{array}{l}\text { Lead tim } \\
\text { Capacity } \\
\text { Layout }\end{array}$ & & & & & \\
\hline $\begin{array}{l}\text { Price } \\
\text { Quality }\end{array}$ & & & & & \\
\hline
\end{tabular}

Region 6:Caters those elements which are highly critical to the final product but have less strategic importance, such products shall also be outsourced with the help of balance score card model as explained in region 1. Factors of balance score card model for this region will be different from region 1 and have been selected considering the fact that activities lying in this region are highly critical to final product.

Method of suppliers' ranking will be the same as described in region 1.

Region 2 and Region 5: The components lying in these regions have quite marginal criticality towards final product however they can be differentiated on the basis of strategic value. The components having high strategic value will lie in region 2 whereas those having comparatively less strategic value will lie in region 5 . For these items, since we have only one parameter that is strategic value to decide we must take help from cost equations in order to get a better result. Therefore, for these two regions we have created another decision matrix having strategic values and cost advantage as its main parameters. The decision matrix shown in figure II is a sub division of region 2 and region 5 . Here $\mathrm{x}$-axis shows strategic value whereas $y$-axis shows the result obtained from cost equation. Discussed below is the decision which can be evaluated from Fig. 3:

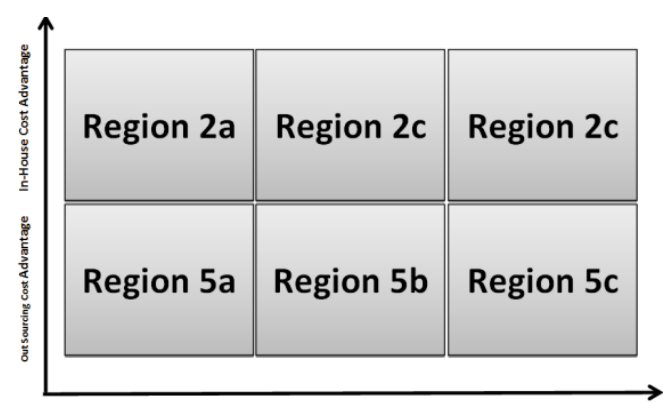

Fig. 3. Decision matrix for marginal values.

Region 2a: Activities lying in this region have low strategic importance and have cost advantage if performed in-house, for such activities if a company can perform them really cheap than only they shall be kept in-house otherwise they shall be outsourced.

Region 5a: Activities lying in this region shall be outsourced without having a second thought, since they have both low strategic value and outsourcing cost advantage.

Region $2 b$ and $5 b$ : Decision of these regions can be made by looking at value of delta since they have marginal strategic value which suggests that activities in region $2 \mathrm{~b}$ shall be kept in house whereas those in $5 \mathrm{~b}$ shall be outsourced.

Region $2 c$ and 5c: Activities in region $2 \mathrm{c}$ shall be kept in-house considering they have high strategic value and in house cost advantage, whereas those in 5c shall be outsourced by using balance score card model shown in table IV, details of which are given under the heading of "Region 1 '"

\section{In-House Cost Calculation}

In house cost comprises of below mentioned costs which must be taken in to account while making decision of components which lie in marginal area of the decision matrix [13]. It can be calculated by using (2).

Labor Cost $(L C)$ : It comprises the cost of labors which are required for manufacturing, it comprises of salaried employees and those involved in core manufacturing processes, However, the cost of other support employees and those helping the administration comes under overhead cost.

Material Cost (MC): It includes cost of the materials required for manufacturing including the cost of logistics required for the movement of that material to desired place.

Overhead Cost $(O C)$ : It includes cost of all of the overheads such as administrative cost, employee incentives, inventory cost, quality checks and other overheads related to manufacturing.

Fixed Cost $(F C)$ : It includes cost of all of the equipments, tools and assets which were used in manufacturing processes. 
TABLE VI: CHECKLIST OF CORE COMPETENCY

Is there need of highly specialized design or labor skills to
perform the activity in consideration?
Whether or not the activity touches the end user's experience to
a high extent?
$\begin{aligned} & \text { Is the activity specialty of your organization and requires } \\ & \text { technical skills which are very rare in market? }\end{aligned}$
$\begin{aligned} & \text { Does the activity allow provision for wide variety of possible } \\ & \text { future markets }\end{aligned}$

$$
\mathrm{TC}_{\text {inhouse }}=M C+L C+F C+O C
$$

All the costs must be entered on per unit basis [14].

\section{Outsourcing Cost Calculations}

Outsourcing cost comprises of below mentioned items which must be taken in account while making decision of outsourcing [15].

Unit Purchase Price (PP): It includes per unit cost of an items which has been negotiated with the buyer

Transportation Cost (TC): It includes per unit cost which vendor charges for transporting the good from his facility to the factory

Administrative Cost $(A C)$ : It includes expenses which were incurred while finding the suitable vendor for outsourcing, moreover it also covers the costs incurred in legal procedures which are required while outsourcing.

Coordinating and Communication Cost $(C C)$ : It covers costs which are incurred while communicating with the vendor regarding sudden rise in demand, change in design or any other issue.

Quality Control Cost (QC): It includes costs which are needed for performing quality checks on outsourced product.

Miscellaneous Cost (MC): All the costs other than those mentioned above come under this category.

$$
\begin{aligned}
\mathrm{TC}_{\text {outsourcing }}= & P P+T C+A C+C C+Q C \\
+ & M C \ldots \\
\Delta & =\mathrm{TC}_{\text {outsourcing }}-\mathrm{TC}_{\text {inhouse }} \ldots
\end{aligned}
$$

If ,

$$
\Delta<0
$$

TABLE VII: BALANCE SCORE CARD MODEL

\begin{tabular}{cccccc}
\hline & \multicolumn{2}{c}{ Rating of suppliers } & \multicolumn{2}{c}{ Ranking of suppliers } \\
\hline Factors & Wt & $\begin{array}{c}\text { Supplier } \\
\text { A }\end{array}$ & $\begin{array}{c}\text { Supplier } \\
\text { B }\end{array}$ & Supplier A & Supplier B \\
\hline Lead time & 9 & 5 & 9 & 45 & 81 \\
Capacity & 8 & 5 & 7 & 40 & 56 \\
Layout & 4 & 4 & 1 & 16 & 4 \\
Price & 8 & 7 & 6 & 56 & 48 \\
Quality & 6 & 6 & 4 & 36 & 24 \\
\hline Total & & & & 193 & 213 \\
\hline
\end{tabular}

Then outsourcing will have advantage, else keep the activity in-house and focus on cost reduction.

\section{IMPLEMENTATION OF FRAMEWORK}

The framework was tested at one of the local electronic appliances manufacturing company which had outsourced a critical component "Shelves" of their refrigerators.

Since the company outsourced the component only on the basis of cost calculations and was facing problems due to supply interruption, therefore we tested the component on our framework to find out any room for improvement.

Since the result of core competency check was negative as shown n Table VI, so the component was tested on decision matrix in order to figure out the region.

The component under consideration is highly critical to the final product but has low strategic value, i.e. according to the decision matrix it lies in region 6. It suggests that the component shall be outsourced but through proper use of balance score card model.

As per model discussed in this work, we asked the company to provide us the potential suppliers from which it inquired pilot lots. The company on the basis of pilot lot sampling opted for supplier ' $A$ ' whereas our calculation (Table VII) shows that supplier ' $B$ ' is the clear winner and should have been awarded the contract. In the next section, the reasons for why the company initially outsourced the component to supplier ' $A$ ' will be presented and also why it's now facing supply interruption problem.

\section{FINDINGS}

The company evaluated the supplier only on the basis of price and quality and did not consider the important parameters such as Lead time and capacity.

Current supplier has high lead time and therefore is unable to match company's requirement.

Current supplier has a lower capacity and therefore is unable to stock inventory for the company, which may be used in case of any urgent requirement arises.

Our result suggested that supplier ' $\mathrm{B}$ ' is much more feasible despite the fact that it has a bit high price and low quality.

Difference in quality is quite meager and can be achieved through proper supplier development.

Since the supplier has excellent lead time and capacity, compromising on a slightly higher cost is worth the price variance.

After the application of the proposed framework, it was analyzed that switching to supplier ' $\mathrm{B}$ ' can save the company from business loss due to supply interruption. Since the component was quite critical to the final product, therefore lead time and capacity have been assigned high weights. The weights and factors of balance score card model may be changed as the requirements of the component under consideration change.

\section{REFERENCES}

[1] M. F. Greaver, "Strategic outsourcing, a structure approach to outsourcing decisions and initiatives," AMACOM Div American Mgmt Assn, 1999. 
[2] M. F. Corbett, The outsourcing revolution: Why it makes sense and how to do it right, illustrated ed., Kaplan Publishing, 2004.

[3] S. E. Fawcett, Supply chain management: From vision to implementation, Pearson Education India, 2008.

[4] B. Vagadia, "Strategic outsourcing: The alchemy to business transformation in a globally converged world," illustrated ed., Springer, 2011.

[5] APICS, "Managing the risks of outsourcing: A survey of current practices and their effectiveness," 2004.

[6] J. Pandya, "Risk, the global age: NGIOA @," Springer, 2012.

[7] T. Kremic, O. I. Tukel, and W. O. Rom, "Outsourcing decision support: A survey of benefit, risks and decision factors," Ohio, Supply Chain Management, 2006.

[8] A. M. A. A. A. Hamzah, "Outsourcing decision processes: A case study of a malaysian firm," African Journal of Business Management, vol. 4 , no. 15 , pp. $3307-3314,2010$.

[9] R. McIvor, "A practical framework for understanding the outsourcing process," Supply Chain Management: An International Journal, vol. 1, no. 5, pp. 22-36, 2000.

[10] S. Ordoobadi, "Development of a decision model for strategic outsourcing," Journal of Applied Business and Economics, 2003.

[11] G. Hamel and C. Prahald, Competing for the future, vol. 6, reprint ed., Harvard Business Press, 1994.

[12] A. Drejer, Strategic management and core competencies: theory and application, illustrated ed., Greenwood Publishing Group, 2002.

[13] R. G. Peter Barrar, Relationships, global outsourcing strategies: An international reference on effective outsourcing, illustrated ed., Gower Publishing, Ltd, 2006.

[14] D. Probert, Developing a make or buy strategy for manufacturing business, illustrated ed., IET, 1997.

[15] S. G. William, Engineering Economy, 14th ed., Pearson Education India, 2009.

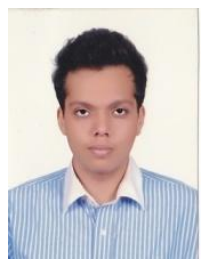

Maaz Ahmed Qureshi was born on 10th September 1989 in Pakistan, He hold bachelors degree in mechanical engineering from NED UET which is one of the finest engineering university in Pakistan. Qureshi is presently working as a supply and planning engineer in a manufacturing industry in Pakistan, his research interests revolve around development of heuristics and frameworks for making supply chain operation more efficient in developing countries.

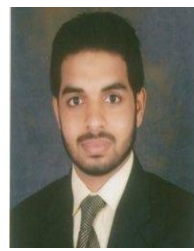

Muhammad Salman was born on 30th June 1987 in Pakistan. He holds masters degree in Industrial management from NED UET which is one of the finest engineering university in Pakistan. Salman is currently working as a planning manager in a manufacturing industry in Pakistan and has recently presented a paper in 19th international conference on Industrial engineering and engineering management having title "Implementing SCOR in Manufacturing Industry of developing country". His research interest revolves around development of stochastic models for making decisions under uncertainty and methods to ensure smooth supply chain operations.

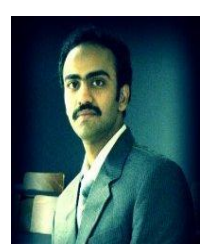

Ramiz Khalid was born in Pakistan and is a PHD in Industrial Engineering with specialty in project management from National Polytechnique de Toulouse (INPT). Khalid has several publications to his credit and is currently associated with NED UET as an associate professor in Department of Industrial engineering. His research interest includes Project Risk Management, Management of Global Projects, Assembly Line Balancing, Aggregate Planning, and Inventory Management. 